\title{
Tightly coupled policies and loosely coupled networks in the governing of flood risk mitigation in municipal administrations
}

\author{
Per Becker ${ }^{1,2,3}$
}

\begin{abstract}
Flood risk is a complex and transboundary issue that is expected to escalate with climate change and requires to be governed by collaborative networks of actors. Municipal administrations have been suggested to have a particularly important and challenging role in such governance. Although collaborative governance has attracted intense scientific attention, empirical studies generally focus either on the macro-level institutions per se, or on the meso-level interaction between organizations, without corresponding attention to the micro-level interactions between the individual actors constituting the organizations and reproducing the institutions. The purpose of this paper is to contribute to the understanding of how flood risk is governed within municipal administrations, by studying how actors interact within them when implementing tightly coupled policies. The paper draws on comparative case study research of three Swedish municipal administrations (Lomma, Lund, and Staffanstorp). Data were collected through interviews with all 143 actors actively contributing to mitigating flood risk within the municipal administrations, and analyzed structurally and interpretatively using social network analysis and qualitative analysis. Although the Swedish legal framework consists of tightly coupled policies demanding coordination between the actors implementing them, there is a recurrent pattern of relative integration between actors implementing policies for planning and water and sewage, and substantial separation between them and actors implementing policy for risk and vulnerability. This cinderellic fragmentation generates a "problem of fit" between the legal framework and the collaborative networks implementing it, which undermines the effectiveness of flood risk mitigation in municipal administrations. It is not accidental but a consequence of a directional separation of institutionalization, where the more bottom-up and problem-oriented institutionalization of practices in planning and water and sewage, and the more top-down and complianceoriented institutionalization of practices in risk and vulnerability pull the network of actors apart. I demonstrate how the mechanisms of increasing returns, commitments, and objectification may all operate simultaneously but to various degrees in different practices across any collaborative governance network. Hence, potentially undermining policy coherence, policy integration, and collaborative governance.
\end{abstract}

Key Words: flood risk; governance; institutional fit; institutionalism

\section{INTRODUCTION}

Flood risk is of great global concern (Grobicki et al. 2015). Although many of the most vulnerable people live in developing countries (Dilley et al. 2005), flood risk is threatening to undermine sustainable development also in the most affluent, advanced liberal democracies (Priest et al. 2016); especially because flood risk is expected to escalate with climate change (IPCC 2012). This has spurred intense scientific interest in the systems governing flood risk across administrative levels (e.g., Hegger et al. 2014, Alexander et al. 2016, Thaler and Levin-Keitel 2016, Cumiskey et al. 2019, Johannessen et al. 2019, Becker 2020a). However, floods are complex phenomena not bounded by administrative borders, levels, or sectors (Niemczynowicz 1999) and any specific flood event can be the result of a combination of pluvial, fluvial, coastal, and groundwater processes (Becker 2014). Risk, on the other hand, is a contested concept that can be defined as uncertainty about what could happen and what the consequences would be (Aven and Renn 2009). The complexity and transboundary nature of flood risk require it to be governed by collaborative networks of actors (Folke et al. 2005, Renn 2008) and the patterns of social relations among these actors have been suggested as fundamental for their collective capacity to mitigate risk (Ingold et al. 2010, Becker 2018). Flood risk has also been suggested a "wicked problem" involving multiple actors with conflicting interests and ambiguity in both problem and solution (Alford and Head 2017) and thus demanding interaction between different actors attempting to address it (Guerrin et al. 2014, Cumiskey et al. 2019). It is in such circumstances that collaborative governance has been suggested particularly important (Ansell and Gash 2008, Bodin et al. 2020).

The fit between the biophysical basis of complex challenges and the social organization of actors attempting to address them has been suggested particularly important for collaborative governance (Folke et al. 2007). Many studies of the governing of water-related issues, therefore, argue for the benefits of focusing on the catchment-level, also referred to as the basin-level (e.g., Niemczynowicz 1999, Borowski et al. 2008, Pahl-Wostl et al. 2012, Lebel et al. 2013, Widmer et al. 2019). However, early thinking about institutional fit was not only concerned with biophysical and organizational compatibility, but also explicitly with the fit of legal frameworks regulating activities (Young and Underdal 1997, Folke et al. 2007). Similar arguments for the importance of connecting and coordinating activities in the implementation of different policies governing flood risk have been framed in terms of policy coherence (Benson and Lorenzoni 2017), integration (Cumiskey et al. 2019, Metz et al. 2020), and overcoming fragmentation (Gilissen et al. 2016). However, these studies generally focus on different organizational actors working in the same or different policy areas and contributing to the same or

${ }^{1}$ Division of Risk Management and Societal Safety, Lund University, Sweden, ${ }^{2}$ Risk and Crisis Research Centre (RCR), Mid Sweden University, Sweden, ${ }^{3}$ Unit for Environmental Sciences and Management, North-West University, South Africa 
different flood risk management strategies, e.g., mitigation, preparedness, and response, while the inner workings of these organizations have received less attention in this context.

Although there are various types of organizations involved in governing water-related issues in a catchment area, municipal administrations have been suggested to have particularly important and challenging roles (Mancilla García et al. 2019). This is especially noticeable in the systems governing flood risk in the Nordic region, with both responsibilities and resources largely decentralized to the municipal level (Harjanne et al. 2016). Considering the typically broad portfolio of water-related responsibilities of municipal administrations (Mancilla García et al. 2019), it is also important to grasp how individual actors interact when engaging in activities to implement different policies within them. This becomes particularly consequential when the different policies demand interaction between actors implementing them, which can be referred to as the policies being tightly coupled (cf. Fusarelli 2002, compare with Bodin and Nohrstedt 2016 on tightly coupled tasks). For instance, policies on dam or levee construction may demand input from actors implementing policies for environmental protection, and policies on urban planning may demand input from actors implementing policies on storm water drainage.

This paper is limited to studying the mitigation of flood risk, which is here defined as comprising all proactive activities that reduce the likelihood of floods and/or their consequences before occurring (Coppola 2011). It is worth noting that this broad definition of flood risk mitigation also includes what sometimes are referred to as flood defense and prevention (Hegger et al. 2014). It does, however, not include activities preparing for effective response or recovery in case of an actual flood, and should not to be confused with how the same term is used in relation to reducing sources or enhancing sinks of greenhouse gases in relation to climate change (IPCC 2015).

Swedish municipal administrations are relatively large and complex organizations, with a multifaceted range of responsibilities related to mitigating flood risk (Becker 2020a) that appeared in legislation in the mid-1980s (SFS 1987:10; SFS 1986:1102; Prop. 1985/86:150 Bil. 3). The Swedish legal framework confers sovereign right to municipal administrations to adopt land use plans (SFS 2010:900), explicitly pointing out considerations for flood risk (Ch.2, Sect.5), and they have the responsibility to remove surface water from settled areas (SFS 2006:412). The legal framework stipulates that municipal administrations must have an action program to mitigate risk (SFS 2003:778), and regularly assess risk and vulnerability within their jurisdiction (SFS 2006:544). The formal guidelines for such municipal action programs and risk and vulnerability analyses both highlight flood risk explicitly (MSB 2011a, b), and the latter states that a main purpose of risk and vulnerability analysis is to provide input to land use planning (MSB 2011a). The Swedish legal framework is thus concentrating the responsibility for governing the mitigation of flood risk to the municipal administration through tightly coupled policies concerning water and sewage, planning, and risk and vulnerability, which demand coordination between the actors implementing them within it (Peters 2013). The Swedish system for governing flood risk has been intensely studied (e.g., Johannessen and Granit 2015, Ek et al. 2016, Becker 2018) and provides a suitable context for also studying the interaction among individual actors contributing to the implementation of tightly coupled policies governing flood risk mitigation within municipal administrations.

Empirical studies of collaborative governance generally focus either on the macro-level institutions per se (e.g., Pahl-Wostl et al. 2012, Guerrin et al. 2014, Alexander et al. 2016), or on the meso-level interaction between organizations (e.g., Bergsten et al. 2014, Guerrero et al. 2015, Widmer et al. 2019), without corresponding attention to the micro-level interactions between the individual actors constituting the organizations and reproducing the institutions through their recurrent actions (Becker 2020b). An explicit focus on the interaction among individual actors contributing to the governing of flood risk mitigation within municipal administrations would thus complement these studies. However, studying individuals in organizations has been an important scientific focus for at least a century (e.g., Taylor 1919, Weber 1978). Regardless how common the early scientific notion of organizations as instruments for rational goal-oriented action still is in society, it has attracted extensive critique for decades (Meyer and Rowan 1977, DiMaggio and Powell 1983). Organizations are not only structured and functioning for rational goal-oriented efficiency. They are also structured and functioning by institutional rules, which can be regulative (e.g., legislation, policy), normative (e.g., norms, expectations), or cultural-cognitive (e.g., schema, frames; Scott 2014). This approach is commonly referred to as new institutionalism (DiMaggio and Powell 1991) and has become influential in organizational analysis (Scott 2014). It has also been suggested a crucial complement for the study of social-ecological interactions (Hotimsky et al. 2006). New institutionalism has proven a useful perspective to explain why networks of actors that comprise logically interdependent parts may end up loosely coupled, or even decoupled (Weick 1976, Meyer and Rowan 1977, DiMaggio and Powell 1983, Scott 2014). It constitutes thus a particularly suitable theoretical perspective for this study. Although it has contributed to our understanding of institutions on macro-, meso-, and micro-level, the purpose of this paper demands particular engagement with micro-oriented approaches (Meyer and Rowan 1977, North 1990, van de Ven and Garud 1994, Zucker and Schilke 2019).

The purpose of this paper is thus to contribute to the understanding of how flood risk is governed in large and complex municipal administrations, by studying how actors interact within them when implementing tightly coupled policies and applying a new institutionalist lens to analyze any emerging patterns. To meet that purpose, I intend to answer the following research question: How are Swedish municipal administrations organizing internally to implement legislation governing flood risk mitigation? This is intended as a Foucauldian "how question" (cf. Foucault 1991). It is thus not only a descriptive question concerning how individual actors interact in this context and how that impacts flood risk mitigation, but also an explanatory question of how they have come to interact in that way.

\section{METHODS}

The research adopts a comparative case study approach (Yin 2003). Three municipalities of varying size, as well as levels of flood risk, were selected within the same catchment area. The 
catchment area was selected using the logic of the extreme case, because cases with bigger challenges "often reveal more information because they activate more actors and more basic mechanisms in the situation studied" (Flyvbjerg 2006:229). However, for a catchment area to be considered extreme has less to do with extreme magnitudes of flood risk and more with the complexity of the flood problem. Höje $\AA$ catchment area in southern Sweden comprises mainly Lomma, Lund, and Staffanstorp municipalities, which are all currently experiencing significant changes in terms of population growth and urbanization, exploitation of new areas, and densification of existing areas. It involves combinations of fluvial, pluvial, coastal, and groundwater floods, with significant impacts of human activity on hydrology. Höje A catchment area was thus selected, with the three municipal administrations of Lomma, Lund, and Staffanstorp constituting the cases for comparison.

The comparative case study integrates structural and interpretive analysis (White 1997) because the roles of actors contributing to flood risk mitigation are defined both by their social relations and by the institutional context they are embedded into (DiMaggio 1992). Social network analysis has proved useful to unravel underlying processes (Robins et al. 2012), while qualitative research is useful to unveil their reasons and meaning (Bernard 2006). Social network analysis and qualitative research were thus applied to study the networks of actors within each municipal administration contributing to the implementation of the legislation governing flood risk mitigation.

Because the boundaries of these networks were unknown from the outset, the participants were selected by means of snowballing (Borgatti et al. 2018). The snowballing started with 10 participants within each municipal administration identified as likely to contribute to the mitigation of flood risk-i.e., representatives to Höje Å River Council and civil servants working with planning, water and sewage, land and exploitation, and environmental issues - using a name-generating question concerning who each participant depends upon for input to be able to contribute to mitigating flood risk. It continued in principle until no more new participants were identified, but involved in practice boundary judgements of relevance (Becker 2018). This resulted in 143 participants contributing actively to mitigating flood risk: 35 within Lomma municipal administration, 88 within Lund municipal administration and VA SYD (the regional water and sewage organization Lund is part of), and 20 participants in Staffanstorp municipal administration. In addition to themselves, the participants identified 86 actors $(16,59$, and 11) on whom they depend for some input, but who are not contributing actively or cannot be interviewed, i.e., people who have died, left the organization, not considering themselves contributing, or performing purely technical tasks (e.g., maintaining a pump, flushing a pipe, etc.). This category also includes one instance per municipal administration of a participant referring to groups instead of an individual, i.e., a municipal call center, VA SYD, and a group of civil servants on a workshop. Two individuals working with planning in Lund, and not excluded by any boundary judgement, refused to participate. This corresponds to a response rate of $99 \%$. Moreover, one of these individuals was only identified as providing input to one participant, and the other to three participants, indicating that none of them was central, and one of them even peripheral, to the governing of flood risk mitigation. The effect of their absence on the validity of the research is thus assumed to be negligible. The interviews were conducted between January 2017 and October 2018.

Studying how individual actors interact within municipal administrations when implementing tightly coupled policies requires operationalizing complex social relations into something that can be empirically observed. Regardless of how the social relations are formed, they denote some kind of dependence after being established (Luhmann 1979). Although there are numerous kinds of dependencies and many ways to operationalize them, Becker (2018) suggests a framework of seven types that was deemed suitable for the purpose of this paper because they comprise a broad range of exchanges between actors that have been suggested important (Table 1).

Table 1. Seven types of input between actors (Becker 2018)

\begin{tabular}{ll}
\hline \hline Input & Reference \\
\hline Reports of activities & Rowley 1997 \\
Equipment and material & Hoang and Antoncic 2003 \\
Funding & Oliver 1991 \\
Technical information & Leifeld and Schneider 2012 \\
Rules and policy & Leifeld and Schneider 2012 \\
Advice and technical support & Hillman et al. 2009 \\
Pepping and moral support & Hoang and Antoncic 2003 \\
\hline
\end{tabular}

The social network data were collected through structured questions posed to the participants during the interviews. The dependence between actors was operationalized as the importance of the seven types of input (Table 1), rated on a fivepoint Likert scale from not at all (0) to extremely important (4) for their contribution to flood risk mitigation. The importance of the seven different inputs were then aggregated and normalized (divided by the maximum possible sum of 28) to produce an aggregate scale between zero (no importance) and one (maximum importance) that was used in the analysis as the strength of the relation between actors (tie strength). Qualitative data were collected through the informal dialogues that ensued when answering the structured questions and the overall conversation about flood risk mitigation, and recorded through notes. Each interview took between 60 and 90 minutes, with a few shorter interviews with actors less engaged in flood risk mitigation. All interviews were done face-to-face to minimize non-responses and to allow for clarifications and probing (Borgatti et al. 2018). The social network data were analyzed with the assistance of the software UCINET (Borgatti et al. 2002) and the qualitative data were analyzed using a series of coding and categorizations (Charmaz 2006).

The social network data were analyzed exploratorily through visualizations and descriptive statistics, and by using three different centrality measures to investigate the contribution each actor makes to the overall structure of the networks (Borgatti et al. 2018). The exploratory analysis was partly done on an aggregate level of groups of actors mainly engaging in activities implementing the three main policy areas governing flood risk mitigation-water and sewage, planning, and risk and vulnerability - as other civil servants engaging in different activities, or as politicians and senior management. These groups are referred to as types of actors and were also vital for the analysis 
Table 2. Proportion and categories of other civil servants, not primarily engaging in planning, water and sewage, or risk and vulnerability activities.

\begin{tabular}{lcl}
\hline \hline Municipal admin. & Proportion & Categories \\
\hline Staffanstorp & $30 \%$ & $\begin{array}{l}4=\text { Roads, land and exploitation, environment, project management } \\
\text { Lund }\end{array}$ \\
& $37 \%$ & $\begin{array}{l}12=\text { Park and nature, children and education, roads and traffic, legal, strategic development, surveying, } \\
\text { housing, building permits, waste management, land and exploitation, environmental protection, } \\
\text { environmental strategy } \\
10=\text { Building permits, finance, property management, roads, parks, GIS, land and exploitation, project } \\
\text { management, surveying, service center }\end{array}$ \\
& $41 \%$ &
\end{tabular}

of the patterns of interaction between individual actors. Centrality measures are commonly used to analyze power structurally (Scott 2004), but have here particular meanings. This is because the studied relations between actors comprise different inputs for actors to be able to contribute to flood risk mitigation. These inputs can thus be seen as resources flowing in the networks, and controlling these resources confers influence to actors in the network (Brass and Burkhardt 1992). In-degree centrality was used to capture local control over resources by summarizing for each actor the total direct dependence of all actors on the inputs from that actor (Borgatti et al. 2018). Directional betweenness centrality was used to operationalize control over resource flows through the networks because it captures the extent each actor falls on the shortest paths between pairs of other actors (Brass and Burkhardt 1992). Finally, in-eigenvector centrality was used to operationalize the influence an actor has over other influential actors in the network (Brass and Burkhardt 1992), by not only considering how dependent they are on the actor's input but also how dependent other actors are on them.

\section{RESULTS}

\section{Interaction between types of actors}

The most striking features of the networks of actors are (1) their relative structural similarity in the presence of interactions on the aggregate level between planning, water and sewage, politicians and senior management, and other civil servants, and (2) seeming dissimilarity in the interactions with actors engaged in risk and vulnerability (Fig. 1). This means that although the former four types of actors are similarly tied to each other across the networks, the latter type of actors engaging in risk and vulnerability is either decoupled or loosely coupled with the rest of the network.

The results show that the actors engaging in activities to implement risk and vulnerability policies in Staffanstorp are not seen as providing any input needed for any of the other types of actors, thus, not being identified by them and included in the network (Fig. 1). Risk and vulnerability actors only interact with the category other civil servants in Lund, while also interacting with water and sewage and getting input from planning and from politicians and senior management in Lomma (Fig. 1). However, when analyzing the relative importance of the interaction between planning, water and sewage, and risk and vulnerability, the three networks exhibit closer resemblance (Table 2).

Actors engaged in planning and in water and sewage interact substantially when contributing to the governing of flood risk mitigation in all three municipal administrations, with substantial proportions of the total importance of inputs from the other types of actors flowing between them (Table 2). This is in sharp contrast to the inputs from actors engaged in risk and vulnerability, which are non-existent, except to water and sewage in Lomma where it is of very little relative importance (Table 2). It is also only in Lomma that the actor engaged in risk and vulnerability activities receives important input from actors engaged in the other two policy areas, and then only a substantial proportion from water and sewage (Table 2). However, qualitative interview data indicate that actors engaged in risk and vulnerability activities are not seen as contributing to the mitigation of flood risk in the municipal administrations, for instance, "He is not even on the playing field concerning floods" (Female civil servant about her risk and vulnerability counterpart).

Fig. 1. Networks of types of actors mitigating flood risk within the three studied municipal administrations. Note that node sizes are set, while tie thicknesses represent the sum of individual ties and are relative within each network and cannot be compared between networks.

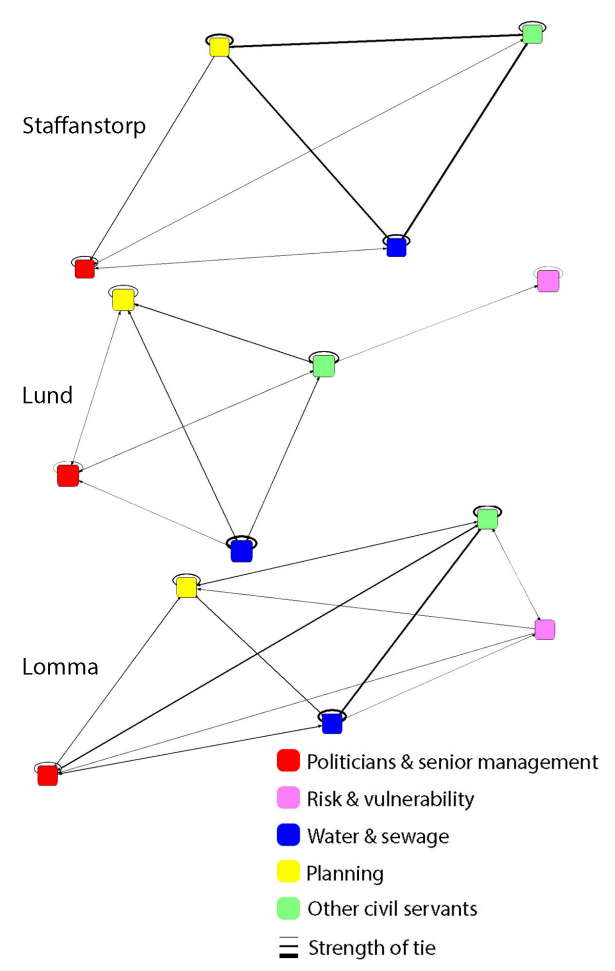




\section{Patterns of interaction between individual actors}

In addition to the aggregate analysis, it is also informative to study patterns of interaction on individual level. Actors engaged in planning and water and sewage are closely interacting and centrally located in the networks of all three municipal administrations (Figs. 2-4). This is also picked up in qualitative data. For example:

Flood and urban drainage are important issues in planning and we have always [water and sewage expert] on board, who manages them. (Female civil servant, Staffanstorp)

We who work with water and sewage are, of course, very dependent on what they [planners] do. ... I trust them fully, but there are difficulties in the contribution of planning to [flood] mitigation in the legislation. (Female civil servant, Lomma)

There are also actors engaged in water and sewage mainly interacting with each other (Figs. 2-4), which is expected of the more technical line management part of their organizations. It is mainly actors engaged in water and sewage who have most local control of resources being exchanged in the networks, operationalized as in-degree centrality (Fig. 2), most control over resource flows through the networks, operationalized as directional betweenness centrality (Fig. 3), and most influence over other influential actors, operationalized as in-eigenvector centrality (Fig. 4). This is also reflected in the first selected quote below, except for an actor engaged in planning with most control over resource flows in Lund, as reflected in the second quote, and an actor among other civil servants in Lomma.

I am not sure if I can help you with this study, since I am not working with floods. I guess you have talked to [water and sewage expert], on the Technical Unit, who takes care of such questions. (Female planner, Staffanstorp)

Among us planners, we can always go to [planner's name] as she is a bit like the spider in the web concerning these issues, with contacts to a lot of people (Female civil servant, Lund)

In Lomma, the most structurally centered actor is instead an environmental strategist, who is identified as providing important input to numerous actors engaging in a wide range of activities (Fig. 2), having much control over resource flows (Fig. 3) and most influence over other influential actors (Fig. 4). This latter point was also explicitly mentioned by several participants during the interviews: "She has the ear of the chairman of the municipal executive board" (Male politician, Lomma); "The politicians trust her" (Female civil servant, Lomma).

The centrality of the environmental strategist in Lomma might be connected to the more central positions of politicians and senior management there than in Lund, and their much more central positions than in Staffanstorp, where such actors are peripheral (Figs. 2-4). It is also interesting to note the structural positions of other civil servants, which are generally least centrally located in Staffanstorp, more central in Lomma, and most central in Lund. The proportion and diversity of other civil servants are also lower in Staffanstorp, with much fewer categories of actors involved in mitigating flood risk (Table 3). Lund and Lomma are more similar in these regards, with slightly higher proportion of other civil servants involved in Lomma and slightly more categories of actors involved in Lund (Table 3). The substantially more mobilized municipal administrations in Lomma and Lund are commonly attributed to the tenacious work of the environmental strategist in the former and to the project "Lund's Water" in the latter. For instance,

Fig. 2. Local control of resources in networks of actors mitigating flood risk within the three studied municipal administrations. Node size $=$ local control of resources (indegree centrality). Tie thickness $=$ normalized sum of importance of inputs. Note that node sizes and tie thicknesses are relative within each network and cannot be compared between networks.

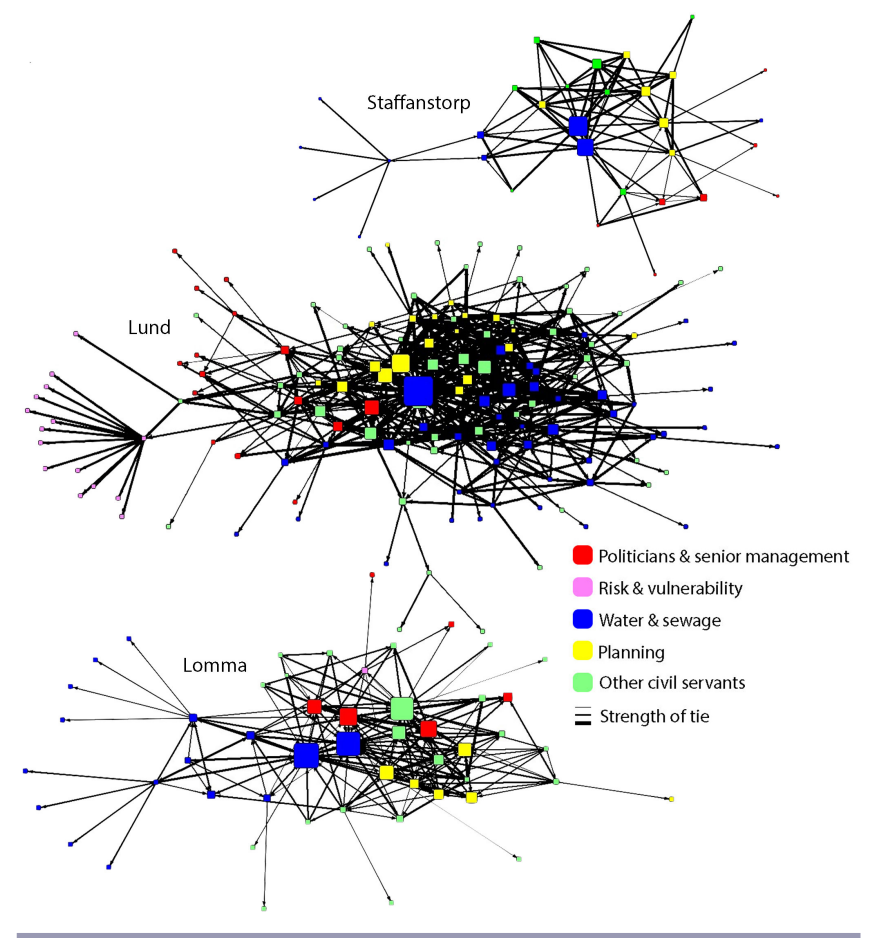

I have worked a long time to get everybody involved. Some came along right away. When the politicians started to think it was important, all managers became interested and then everybody was involved shortly thereafter. ... More or less interested. (Female civil servant, Lomma)

Five years ago, we didn't see this as our responsibility. Now, it is a top priority and we work closely together with other departments to see where the money we have would be put to best use to solve the problem. (Male civil servant, Lund)

There are differences between the municipal administrations concerning the structural positions of actors engaged in risk and vulnerability activities (Figs. 2-4) that are more essential for the purpose of this paper. Although identified in the aggregate analysis above (Fig. 1), analyzing patterns of interaction between individual actors provides additional input to grasp these differences; at least for Lund and Lomma, where risk and 
Table 3. Proportion of total importance of input from other types of actors.

\begin{tabular}{|c|c|c|c|c|}
\hline Receiver & Provider & Staffanstorp & Lund & Lomma \\
\hline Planning & Water \& sewage & $44 \%$ & $47 \%$ & $28 \%$ \\
\hline Water \& sewage & Planning & $38 \%$ & $32 \%$ & $33 \%$ \\
\hline Planning & Risk \& vulnerability & - & $0 \%$ & $0 \%$ \\
\hline Water \& sewage & Risk \& vulnerability & - & $0 \%$ & $3 \%$ \\
\hline Risk \& vulnerability & Planning & - & $0 \%$ & $8 \%$ \\
\hline Risk \& vulnerability & Water \& sewage & - & $0 \%$ & $44 \%$ \\
\hline
\end{tabular}

Fig. 3. Control over resource flows in networks of actors mitigating flood risk within the three studied municipal administrations. Node size $=$ control over resource flows (directional betweenness centrality). Tie thickness $=$ normalized sum of importance of inputs. Note that node sizes and tie thicknesses are relative within each network and cannot be compared between networks.

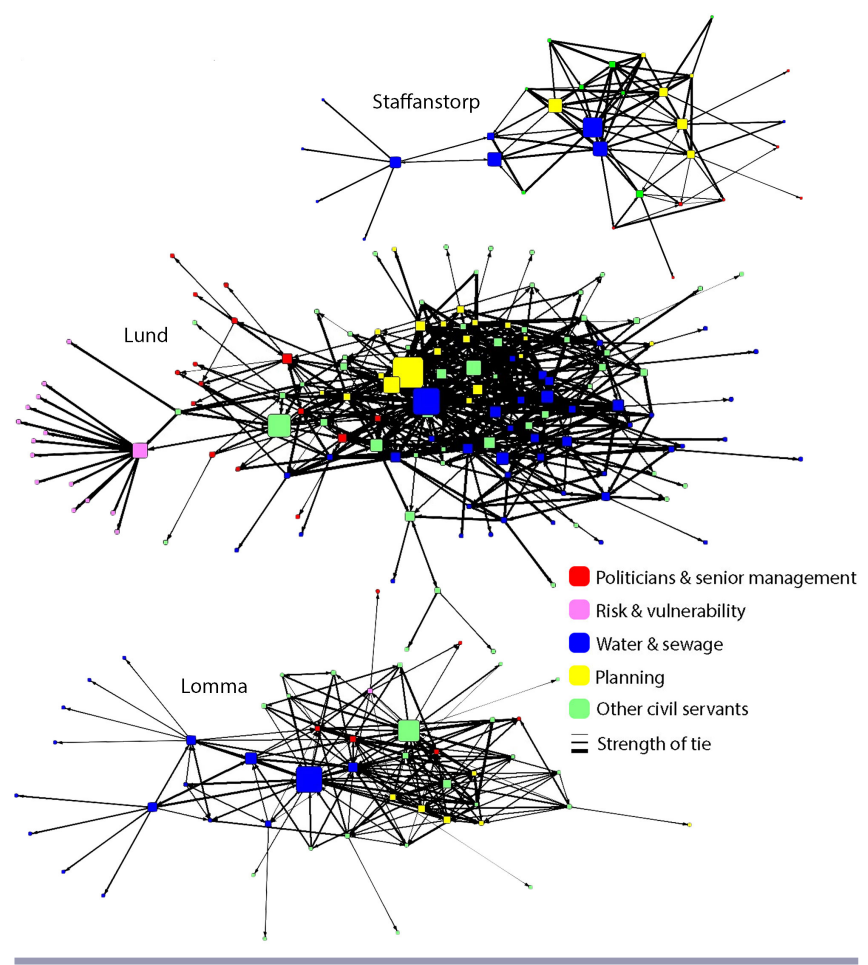

vulnerability actors are involved to some extent. There are a number of actors engaged in risk and vulnerability activities in Lund, but only two provide input to two other civil servants (Figs. $2-4)$. This is particularly interesting as the bulk of these actors are actually focal points working for different departments or other municipal organizations. These focal points are intended to be the liaisons between their departments and risk and vulnerability activities, but are never once mentioned as providing input to anybody involved in flood risk mitigation. The only links to actors involved in planning or water and sewage are indirect through other civil servants, who are relatively unimportant locally (Fig. 2) and with little influence over other influential actors (Fig. 4). Very few participants indicate any awareness or
Fig. 4. Influence over influential actor in networks mitigating flood risk within the three studied municipal administrations. Node size $=$ influence over influential actors (in-eigenvector centrality). Tie thickness $=$ normalized sum of importance of inputs. Note that node sizes and tie thicknesses are relative within each network and cannot be compared between networks.

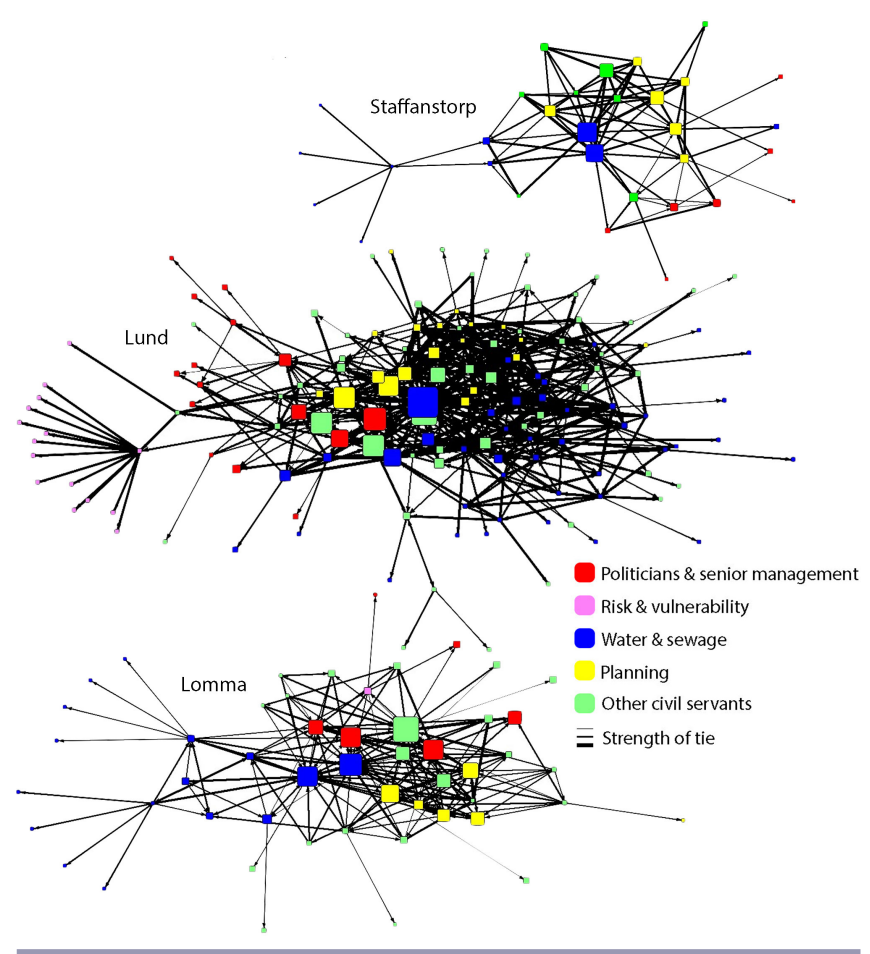

concern about this lack of integration of actors engaging in implementing the tightly coupled policies, with one particularly notable exception:

This is an interesting study because it is obvious that we are divided in a way that hinders the management of complex challenges, but how should we otherwise be organized? With "The Boss of It All" [reference to Danish director von Trier's comedy film "Direktøren for det hele"]? (Male senior manager, Lund)

In Lomma, on the other hand, there is one actor engaged in risk and vulnerability activities, who provides somewhat important input directly to one actor and receives rather important input from another actor engaged in water and sewage, and receives unimportant input from one actor engaged in planning. 


\section{Outcomes in terms of policy intentions}

Although the three municipal administrations differ in the level of interaction between actors engaged in risk and vulnerability and in planning or water and sewage, from none in Staffanstorp, only indirectly in Lund, and also directly in Lomma, the outcomes are similar in terms of failure to fulfil the integrative intentions of the legal framework. The results of the qualitative parts of the interviews are unambiguous. Neither land use planning, nor urban drainage and storm water management, are informed at all by risk and vulnerability analysis in any of the municipal administrations, and neither risk and vulnerability analysis nor the municipal action programs consider the impacts of planning or water and sewage on flood risk. Some participants provide explanations for this, which are particularly interesting for the purpose of this paper:

Yes, it is perhaps problematic, but that is how planning must be done. How should flood risk be assessed otherwise? The law says that it is the landowner who must show that flood risk is taken into account and they pay for the necessary assessments. They cannot be forced to pay for assessments of flood risk for areas bigger than the area they own and have requested a detailed development plan for. Who should pay for it then? This is how planners in Sweden do it. (Female civil servant, Lomma)

No, but this is how it is done in Sweden. All municipalities must regularly do a risk and vulnerability analysis and submit it. We have worked hard to build a good system for it here in Lund and we have now representatives involved in all departments. There is still work to do, but I think we are on the right way and we get the job done. (Male civil servant, Lund)

In stark contrast to this, planning and water and sewage are influencing each other heavily, as detailed development plans are never approved without explicit consideration of urban drainage and storm water management, and no urban drainage and storm water management system is ever designed without considering land use. For instance,

Floods are a priority in the building of new areas, but it is taken care of in the projects. Water and sewage expertise is always involved in the planning to make sure the drainage system for the new area is correct. (Female civil servant, Staffanstorp)

Water has always been considered, but when floods became a higher priority we had to try new ways of working together. Also now, with the project "Lund's Water". We find a way that works, and stick to it. This is how we do it. (Male civil servant, Lund)

\section{DISCUSSION}

The results reveal interesting patterns of how Swedish municipal administrations organize for the governing of flood risk mitigation. Regardless of differences in size and flood exposure, the three municipal administrations share many structural features. This is particularly striking in their formal organization, with nearly identical functions officially defined albeit aggregated and named slightly differently upward in the administrative hierarchies. This is, however, not surprising, but rather expected considering the rich literature on the institutionalist notion of isomorphism (Meyer and Rowan 1977, DiMaggio and Powell 1983, Scott 2014), which is "the result of processes that make organizations more similar without necessarily making them more efficient" (DiMaggio and Powell 1983:147). The results are also showing relative isomorphism in the interaction between actors engaged in planning, water and sewage, and risk and vulnerability, while the positions of politicians and senior management, and of other civil servants, vary substantially between the three municipal administrations. Most notably the differences in structural positions of politicians and senior management, who are most peripheral in Staffanstorp, more central in Lund, and most central in Lomma, as well as in the diversity and centrality of other civil servants, who are much less diverse and central in Staffanstorp than in Lomma and Lund (Figs. 2-4 and Table 3). These differences are interesting to discuss in themselves (Petridou et al. 2021), but in this paper I focus primarily on the organizing to implement the legislations for planning, water and sewage, and risk and vulnerability, which are essential for the mitigation of flood risk and tightly coupled to each other.

It is then particularly interesting to note a recurrent pattern of relative integration between actors implementing the two former, while the actors implementing the latter are loosely coupled or even decoupled from them. Although there are differences in the extent of structural decoupling among the municipal administrations - from no interaction between actors engaged in activities implementing policies for risk and vulnerability and for the other two policy areas in Staffanstorp, only indirect interaction in Lund, to also minor direct interaction in Lomma - the qualitative results clearly suggest similarity in terms of not using any input across this divide. This pattern of concurrent integration and separation is referred to as cinderellic fragmentation, which is not accidental or merely structural, but a consequence of parallel processes of institutionalization.

\section{Cinderellic fragmentation}

It is clear that the actors engaged in planning and in water and sewage are interacting relatively intensely with each other when contributing to the governing of flood risk mitigation in all three municipal administrations. It is equally clear that the actors engaged in risk and vulnerability are hardly interacting with any of them, if at all. This is commonly referred to as fragmentation (Feiock and Scholz 2010) and has been suggested as a common feature in the governing of flood risk on institutional (macro) and organizational (meso) levels (e.g., Gilissen et al. 2016, Cumiskey et al. 2019, Metz et al. 2020). However, the micro-level collaborative networks governing the mitigation of flood risk within the municipal administrations are neither fully integrated in terms of interactions between actors implementing the three main and tightly coupled legislations, nor entirely fragmented (Figs. 2-4 and Table 2). It is not possible to meaningfully describe the level of integration or fragmentation on a scale between these two extremes either, as parts of the networks exhibit close interaction at the same time as other parts are loosely coupled or even decoupled. This pattern of relative integration between two types of actors that are more or less completely separated from a third type of actor alludes to the fairy tale of Cinderella and her two stepsisters. Although "Cinderella" is included in the Oxford English Dictionary (2014), meaning "a person or thing that is 
undeservedly neglected or ignored," the analogy is here more intricate and relational. It is more relational in the sense of cinderellic fragmentation emerging in the transactions among all actors (cf. Emirbayer 1997) and not caused by particular scheming "stepsisters," and it is more intricate in the sense of the processes behind this kind of fragmentation.

The results reveal that actors engaged in risk and vulnerability are not neglected or ignored more by actors engaged in planning or water and sewage than they neglect or ignore these actors themselves. They are simply working on their own to comply with the requirements of the legislation they are tasked to implement, with the main indicators of compliance being the production and submission of a municipal action program (SFS 2003:778) and risk and vulnerability analysis (SFS 2006:544). Although all three municipal administrations submit these outputs, nobody uses them to inform planning or water and sewage as intended in policy. This concurs fully with previous research (Lin and Abrahamsson 2015) and appears to be a general feature of Swedish municipal administrations. However, the actors engaged in planning or water and sewage are also focusing on meeting the requirements of the legislations for their respective policy areas, but instead with intense interaction with each other because both compliance and current practices demand collaboration.

This cinderellic fragmentation, with concurrent integration and separation within the same collaborative networks of actors, generates a "problem of fit" between the legal framework and the collaborative networks implementing it. Such problems of fit have been shown to potentially undermine effective problem-solving in a wide range of contexts (Bodin and Nohrstedt 2016, Bergsten et al. 2019). Moreover, the pattern of cinderellic fragmentation is not a coincidence. It is the result of parallel processes of institutionalization that are separated in both their foundation and orientation.

\section{Directional separation of institutionalization}

The legal framework started to explicitly demand considerations of flood risk in planning and water and sewage in the mid-1980s (SFS 1987:10; SFS 1986:1102; Prop. 1985/86:150 Bil. 3) and risk and vulnerability analysis in the mid-2000s (SFS 2006:544). However, the mere temporal difference, with actors implementing the two former having more than twice as long a history together than with the actors implementing the latter, might not be a main reason for cinderellic fragmentation. This is particularly unlikely because flood risk mitigation became a prioritized issue in the studied cases as late as 2007, when all three policy areas were in place. Bodin and colleagues (2019) demonstrate the importance of pre-existing relations for structuring collaborative networks of individual actors, but theoretical perspectives of new institutionalism suggest that qualitative time-related factors may be more informative than purely quantitative differences in the age of the three policy areas. Stinchcombe (2000) was the first to propose the importance of initial social conditions on the development of the structure of an organization over time, and others point out the significance of a few decisive events on national- (Scott 2014) or even global level (Drori et al. 2006). It is clear that past social conditions and significant floods elsewhere in Sweden and Europe have played decisive roles in shaping the legal framework, as well as the more recent string of floods closer to home in making flood risk mitigation a priority. However, such determinant and structural top-down explanations of institutionalization fail to elucidate the pattern of cinderellic fragmentation, which requires keener attention to the agency of the involved actors.

Instead of looking for explanation solely in a few macro-level conditions and events, van de Ven and Garud (1994) suggest paying attention to the many micro-level events in which actors faced with a new situation coinvent ways to deal with it. They argue that after a period of events with behavioral variation, as actors test and adjust activities as they go along, some patterns of activities start to be selected more and more often than others (rule-making events) until they dominate and become the convention (rule-following events). This resonates strikingly well with the empirical material. The institutionalization of flood risk mitigation is neither detached from the past, nor unfolding in a vacuum. The practices of actors engaging in ensuring sufficient urban drainage for more everyday rainfall, which have included both planning and water and sewage for decades, have been structuring the practices of flood risk mitigation by providing initial patterns of activities. The actors involved from the start are then coinventing updated practices together, with significant costs in terms of time, energy, and resources. North (1990) calls this "large setup costs," and provides an explanation based on "increasing returns" for why systemic flaws in the current practices of mitigating flood risk are not addressed even when they are obvious to involved actors. This explanation is emphasizing the role of incentives and argues that flawed practices continue because further work in the same direction is still rewarded, while the costs of changing to an alternative increase over time (Scott 2014). This is particularly common in contexts where feedback is fuzzy and evaluations subjective (North 1990), such as in the mitigation of flood risk in the municipal administrations. Status quo is then maintained through a combination of actors being reluctant to consider alternatives after having invested time and energy to learn the current practices (learning effects), the contribution of each actor being facilitated by others following the same practices (coordination effects), and new actors being motivated to adopt the current practices as they appear commonly accepted (adaptive expectations; North 1990). This would also explain why actors engaging in risk and vulnerability are not entering, invited, or allowed into the more intensely interacting part of the network of actors engaging in planning and water and sewage, even when the policies are tightly coupled, because organizational decoupling is more likely when there are high costs associated with closer integration (Scott 2014).

Although actors engaged in planning and water and sewage were already interacting to address water-related issues before the relatively recent problematization of flood risk mitigation, and continued to invest in modified but congruent practices, actors engaged in risk and vulnerability appeared first after the legislation was passed and found themselves having to produce the first municipal action programs and risk and vulnerability analyses almost immediately. These actors thus had to do it more or less completely on their own, with very limited involvement and interest of other actors within the municipal administrations (Lin and Abrahamsson 2015), but with results that complied with the legislation to the liking of politicians and managers. These early activities and positive feedback in relation to the new demands have clear implications for the institutionalization of 
practices because they constitute rule-making events that set its initial direction (cf. van de Ven and Garud 1994). This direction is then likely to prevail because of the path dependency resulting from North's (1990) learning effects, coordination effects, and adaptive expectations, introduced above. The activities of the actors engaged in risk and vulnerability are also funded by earmarked funding from the national level, which further cements their decoupled activities in relation to the actors engaged in planning and water and sewage. The result comprises practices in risk and vulnerability geared toward ceremonial compliance (cf. Meyer and Rowan 1977), more or less completely devoid of their original purpose (cf. Lin and Abrahamsson 2015).

In addition to incentives in relation to "increasing returns," the results suggest that explanations of the cinderellic fragmentation of actors implementing the three tightly coupled policies can also be found in increasing commitment to professional norms and identities and in increasing objectification of flood risk mitigation, indicated by how the participants express themselves in the interviews. Selznick (1992) suggests that it is not only through incentives that institutions are holding actors hostage to their own history, but through their normative order that is both constituting and being constituted by the actions of contributing actors over time. This is clear in the empirical material, with participants expressing in different ways that this is the way we do it and giving references to the common practices of their different professional groups (cf. Scott 2014). Although closely related to coordination effects (North 1990), such normative expectations are invaluable as they "reduce the need for constant negotiation of expectations and behavioural contracts" (Handmer and Dovers 2007 p. 30), but can clearly also bind actors to flawed practices. The empirical material is also rife with examples of participants expressing that this is how it is done, which is a usual indicator of more cultural-cognitive elements of institutionalization (Berger and Luckmann 1966, Scott 2014). Here it is not about incentives or identity, but about the objectification of shared ideas about central aspects of flood risk mitigation. Such objectification involves the development and diffusion of some degree of consensus among actors concerning the meaning and value of the ideas, where the diffusion shifts from mere imitation to being increasingly normative with less and less room for alternative views (Tolbert and Zucker 1996). These shared ideas thus thicken and harden when diffused, not only for the newly incorporated actors, but also for the actors already subscribing to the particular understanding (Berger and Luckmann 1966).

To summarize, although pre-existing relations are important for structuring collaborative networks of individual actors (Bodin et al. 2019), the pattern of cinderellic fragmentation of flood risk mitigation can be explained by attention to mechanisms behind its institutionalization related to incentives, identities, and ideas. It is indeed common in most empirical studies of institutionalization to find varying combinations of elements, and it is when they align that their combined force is most formidable (Scott 2014). The observed pattern of concurrent integration and separation of actors engaging in planning and water and sewage, on the one hand, and in risk and vulnerability, on the other, may thus best be explained in terms of parallel processes of institutionalization with emphases on different regulative, normative, and cultural-cognitive elements. Although present policy for risk and vulnerability explicitly demands interaction with the other two tightly coupled policy areas, it is possible to submit the main indicators of compliance without genuine interaction with them. When that is repeatedly done over the years, with little or no interest of busy actors engaged in planning and water and sewage and positive feedback from politicians and managers, the decoupled practices get institutionalized with normative and cultural-cognitive backings. This decoupling is also institutionalized in the practices of actors engaging in planning and water and sewage, who set out to address flood risk mitigation together due to pre-existing relations, without needing to include actors engaged in risk and vulnerability. It is again normative and cultural-cognitive elements that trump the regulative elements in the legal framework, but this time they demand close interaction between actors engaging in planning and water and sewage, while practices in risk and vulnerability are allowed to be decoupled. The resulting pattern of cinderellic fragmentation of flood risk mitigation is thus in line with Scott's seminal finding that practices are more likely to be decoupled in an organization when confronted with external regulatory requirements, than with normative or cognitive-cultural demands for integration (Scott 2014).

\section{CONCLUSION}

Therefore, how are Swedish municipal administrations organizing to implement legislation governing flood risk mitigation? Although the Swedish legal framework consists of tightly coupled policies demanding coordination between the actors implementing them, there is a recurrent pattern of relative integration between actors engaging in activities to implement policies for planning and water and sewage and substantial separation between them and actors implementing policy for risk and vulnerability. This cinderellic fragmentation generates a "problem of fit" between the legal framework and the collaborative networks implementing it, which undermines the effectiveness of flood risk mitigation in municipal administrations by decoupling activities that are intended in policy to inform each other. The concept of cinderellic fragmentation may be useful for studies of policy networks and collaborative governance in general because it captures patterns of interaction that are not possible to meaningfully describe on a more conventional scale between fully integrated and entirely fragmented, as parts of the networks may exhibit close interaction at the same time as other parts are loosely coupled or even decoupled. Moreover, cinderellic fragmentation is not accidental but a consequence of a directional separation of institutionalization, where the more bottom-up and problem-oriented institutionalization of practices concerning flood risk mitigation in planning and water and sewage and the more top-down and compliance-oriented institutionalization of practices in risk and vulnerability pull the network of actors apart. The most important contribution to the available literature on policy coherence, policy integration, and overcoming fragmentation in collaborative governance is, however, the mechanisms of the institutionalization demonstrated in this paper. Although these mechanisms of increasing returns, commitments, and objectification are all recurrent themes in new institutionalism, in this paper I demonstrate how they may all operate simultaneously but to various degrees in different practices across any collaborative governance network. This has important implications for the governing of flood risk mitigation, 
and perhaps even for collaborative governance in general because it not only suggests a particular kind of fragmentation that may undermine governance, but also the mechanisms explaining such fragmentation. Although it is crucial to identify detrimental fragmentation in itself, it is by increasing the understanding of the underlying processes that the paper has the greatest potential to support efforts to find leverage points toward closer integration in collaborative governance.

Social network analysis has proven immensely useful for investigating a range of issues and contexts of collaborative governance, out of which I only cite a few important contributions. It is, however, important to remember that most such studies focus on the institutional level (macro) or on the interaction between organizations (meso), and may miss important micro-level relations and processes that are invisible to such approaches. Although combining quantitative and qualitative methods is increasingly common today, most conventional studies of collective governance are only collecting data from individual participants as representatives of organizations (e.g., municipal administrations, departments, divisions, project teams), who are asked if their organizations interact or not. This approach disregards the social relations within organizations that proved to be crucial to grasp governance in the present study. Moreover, it simplifies the social relations between organizations, regardless of level, to the extent that the data becomes thoroughly misleading, for instance, by ignoring the internal structural position of the actors linking two organizations. These arguments find solid theoretical backing from diverse sources. Ahrne (1994:28) asserts that "organizations cannot speak or move; they have no legs to walk with, and no eyes to see with. When organizations do something it is always individuals who act." These actors do not act for themselves, but on behalf of their organizations in inter-organizational relations (Johansson 2008). Studying inter-organizational relations, therefore, presupposes studying interacting individual actors who represent their organizations. However, as Callon and Latour (1981) suggest, individual actors do not represent their organizations equally, and may be unequally successful in translating the interests, desires, and forces of other actors with whom they form alliances or argue. A systematic description of inter-organizational relations relies, therefore, not on paying attention to only one arbitrarily selected pair of individual actors who happen to interact across some boundary, but to all such pairs. Adopting the social relation between individual actors as the fundamental unit of analysis opens up the study of the microlevel relations and processes behind the phenomena of interest, and constitutes thus a crucial complement to more conventional meso- or macro-level studies of collaborative governance.

It is important to note that collecting data on the social relations between individual actors quickly becomes immensely timeconsuming for the often large and difficult delimiting of networks of actors contributing to the governance of complex issues. This is a disadvantage of the approach advocated here because it may push studies to either become reductionist in the sense of only studying an arbitrary part of a much larger network of actors, or to settle for a low response rate that undermines validity because whole network approaches are exceptionally sensitive to missing data. However, its potential contributions to our understanding of collective governing outweighs its resource intensity; not only for studies of interaction within organizations, as showcased in this paper, but also for unpicking the complexities of the interaction between organizations that conventional macro- or meso-level studies may miss or even gloss over to the detriment of their theoretical contributions. Further research is thus needed into the micro-level interaction behind the meso- and macro-level phenomena of collective governing on which contemporary empirical studies commonly focus.

Responses to this article can be read online at: https://www.ecologyandsociety.org/issues/responses. $\mathrm{php} / 12441$

\section{Acknowledgments:}

This study would not have been possible without the keen participation of the politicians and civil servants of Lomma, Lund, and Staffanstorp municipal administrations. The study is part of the research project "Sustainable Urban Flood Management," which is funded by FORMAS (942-2015-149). I would like to thank the two anonymous reviewers for their diligent scrutiny and constructive suggestions.

\section{Data Availability:}

The data collected for this paper will be made available in anonymized form upon request.

\section{LITERATURE CITED}

Ahrne, G. 1994. Social organizations: interaction inside, outside and between organizations. SAGE, London, UK.

Alexander, M., S. Priest, and H. Mees. 2016. A framework for evaluating flood risk governance. Environmental Science \& Policy 64:38-47. https://doi.org/10.1016/j.envsci.2016.06.004

Alford, J., and B. W. Head. 2017. Wicked and less wicked problems: a typology and a contingency framework. Policy and Society 36(3):397-413. https://doi.org/10.1080/14494035.2017.1361634

Ansell, C., and A. Gash. 2008. Collaborative governance in theory and practice. Journal of Public Administration Research and Theory 18(4):543-571. https://doi.org/10.1093/jopart/mum032

Aven, T., and O. Renn. 2009. On risk defined as an event where the outcome is uncertain. Journal of Risk Research 12:1-11. https://doi.org/10.1080/13669870802488883

Becker, P. 2014. Sustainability science: managing risk and resilience for sustainable development. Elsevier, Amsterdam, The Netherlands.

Becker, P. 2018. Dependence, trust, and influence of external actors on municipal urban flood risk mitigation: the case of Lomma Municipality, Sweden. International Journal of Disaster Risk Reduction 31:1004-1012. https://doi.org/10.1016/j.ijdrr.2018.09.005

Becker, P. 2020a. Fragmentation, commodification and responsibilisation in the governing of flood risk mitigation in 
Sweden. Environment and Planning C: Politics and Space 39 (2):393-413. https://doi.org/10.1177/2399654420940727

Becker, P. 2020b. The problem of fit in flood risk governance: regulative, normative, and cultural-cognitive deliberations. Politics and Governance 8(4):281-293. https://doi.org/10.17645/ pag.v8i4.3059

Benson, D., and I. Lorenzoni. 2017. Climate change adaptation, flood risks and policy coherence in integrated water resources management in England. Regional Environmental Change 17 (7):1921-1932. https://doi.org/10.1007/s10113-016-0959-6

Berger, P. L., and T. Luckmann. 1966. The social construction of reality. Penguin Books, London, UK.

Bergsten, A., D. Galafassi, and Ö. Bodin. 2014. The problem of spatial fit in social-ecological systems: detecting mismatches between ecological connectivity and land management in an urban region. Ecology and Society 19(4):6. https://doi. org/10.5751/ES-06931-190406

Bergsten, A., T. S. Jiren, J. Leventon, I. Dorresteijn, J. Schultner, and J. Fischer. 2019. Identifying governance gaps among interlinked sustainability challenges. Environmental Science \& Policy 91:27-38. https://doi.org/10.1016/j.envsci.2018.10.007

Bernard, H. R. 2006. Research methods in anthropology: qualitative and quantitative approaches. AltaMira Press, Lanham, Maryland, USA.

Bodin, Ö., M. Mancilla García, and G. Robins. 2020. Reconciling conflict and cooperation in environmental governance: a social network perspective. Annual Review of Environment and Resources 45:471-495. https://doi.org/10.1146/annurevenviron-011020-064352

Bodin, Ö., and D. Nohrstedt. 2016. Formation and performance of collaborative disaster management networks: evidence from a Swedish wildfire response. Global Environmental Change 41:183-194. https://doi.org/10.1016/j.gloenvcha.2016.10.004

Bodin, Ö., D. Nohrstedt, J. Baird, R. Summers, and R. Plummer. 2019. Working at the "speed of trust": pre-existing and emerging social ties in wildfire responder networks in Sweden and Canada. Regional Environmental Change 19(8):2353-2364. https://doi. org/10.1007/s10113-019-01546-Z

Borgatti, S. P., M. G. Everett, and L. C. Freeman. 2002. Ucinet for Windows: software for social network analysis. Analytic Technologies, Harvard, Massachusetts USA.

Borgatti, S. P., M. G. Everett, and J. C. Johnson. 2018. Analysing social networks. SAGE, London, UK.

Borowski, I., J. Le Bourhis, C. Pahl-Wostl, and B. Barraqué. 2008. Spatial misfit in participatory river basin management: effects on social learning, a comparative analysis of German and French case studies. Ecology and Society 13(1):7. https://doi.org/10.5751/ ES-02341-130107

Brass, D. J., and M. E. Burkhardt. 1992. Centrality and power in organizations. Pages 191-215 in N. Nohria and R. G. Eccles, editors. Networks and organizations: structure, form, and action. Harvard Business School Press, Boston, Massachusetts, USA.

Callon, M., and B. Latour. 1981. Unscrewing the big Leviathan: how actors macro-structure reality and how sociologists help them to do so. Pages 277-303 in K. D. Knorr-Cetina and A. V. Cicourel, editors. Advances in social theory and methodology: toward an integration of micro- and macro-sociologies. Routledge, London, UK.

Charmaz, K. 2006. Constructing grounded theory: a practical guide through qualitative analysis. SAGE, London, UK.

Coppola, D. P. 2011. Introduction to international disaster management. Butterworth-Heinemann (Elsevier), Oxford, UK.

Cumiskey, L., S. J. Priest, F. Klijn, and M. Juntti. 2019. A framework to assess integration in flood risk management: implications for governance, policy, and practice. Ecology and Society 24(4):17. https://doi.org/10.5751/ES-11298-240417

Dilley, M., R. S. Chen, U. Deichmann, A. L. Lerner-Lam, and M. Arnold. 2005. Natural disaster hotspots: a global risk analysis. World Bank, Washington, D.C., USA. https://doi. org/10.1596/0-8213-5930-4

DiMaggio, P. J. 1992. Nadels paradox revisited: relational and cultural aspects of organizational structure. Pages 118-142 in N. Nohria and R. G. Eccles, editors. Networks and organizations: structure, form, and action. Harvard Business School Press, Boston, Massachusetts, USA.

DiMaggio, P. J., and W. W. Powell. 1983. The iron cage revisited: institutional isomorphism and collective rationality in organizational fields. American Sociological Review 48 (2):147-160. https://doi.org/10.2307/2095101

DiMaggio, P. J., and W. W. Powell. 1991. Introduction. Pages 1-38 in W. W. Powell and P. J. DiMaggio, editors. The new institutionalism in organizational analysis. University of Chicago Press, Chicago, Illinois, USA.

Drori, G. S., J. W. Meyer, and H. Hwang, editors. 2006. Globalization and organization: world society and organizational change. Oxford University Press, Oxford, UK.

Ek, K., S. Goytia, M. Pettersson, and E. Spegel. 2016. Analysing and evaluating flood risk governance in Sweden: Adaption to climate change? STAR-FLOOD Consortium, Utrecht, The Netherlands.

Emirbayer, M. 1997. Manifesto for a relational sociology. American Journal of Sociology 103:281-317. https://doi. org/10.1086/231209

Feiock, R. C., and J. T. Scholz, editors. 2010. Self-organizing federalism: collaborative mechanisms to mitigate institutional collective action dilemmas. Cambridge University Press, Cambridge, UK. https://doi.org/10.1017/CBO9780511642319

Flyvbjerg, B. 2006. Five misunderstandings about case-study research. Qualitative Inquiry 12(2):219. https://doi. org/10.1177/1077800405284363

Folke, C., T. Hahn, P. Olsson, and J. Norberg. 2005. Adaptive governance of social-ecological systems. Annual Review of Environment and Resources 30:441-473. https://doi.org/10.1146/ annurev.energy.30.050504.144511

Folke, C., L. Pritchard, F. Berkes, J. Colding, and U. Svedin. 2007. The problem of fit between ecosystems and institutions: ten years later. Ecology and Society 12(1):30. https://doi.org/10.5751/ ES-02064-120130 
Foucault, M. 1991. Question of method. Pages 73-86 in G. Burchell, C. Gordon, and P. Miller, editors. The Foucault effect: studies in governmentality, with two lectures by and an interview with Michel Foucault. Harvester Wheatsheaf, London, UK.

Fusarelli, L. D. 2002. Tightly coupled policy in loosely coupled systems: institutional capacity and organizational change. Journal of Educational Administration 40(6):561-575. https:// doi.org/10.1108/09578230210446045

Gilissen, H. K., M. Alexander, J.-C. Beyers, P. Chmielewski, P. Matczak, T. Schellenberger, and C. Suykens. 2016. Bridges over troubled waters: an interdisciplinary framework for evaluating the interconnectedness within fragmented flood risk management systems. Journal of Water Law 25(1):12-26.

Grobicki, A., F. Macleod, and F. Pischke. 2015. Integrated policies and practices for flood and drought risk management. Water Policy 17:180-194. https://doi.org/10.2166/wp.2015.009

Guerrero, A. M., Ö. Bodin, R. R. J. McAllister, and K. A. Wilson. 2015. Achieving social-ecological fit through bottom-up collaborative governance: an empirical investigation. Ecology and Society 20(4):41. https://doi.org/10.5751/ES-08035-200441

Guerrin, J., G. Bouleau, and F. Grelot. 2014. "Functional fit" versus "politics of scale" in the governance of floodplain retention capacity. Journal of Hydrology 519:2405-2414. https://doi. org/10.1016/i.jhydrol.2014.08.024

Handmer, J. W., and S. Dovers. 2007. The handbook of disaster and emergency policies and institutions. Earthscan, London, UK. https://doi.org/10.4324/9781849773065

Harjanne, A., E. Pagneux, L. Flindt Jørgensen, A. Perrels, P. van der Keur, F. Nadim, J. K. Rød, and E. Raats. 2016. Resilience to natural hazards: an overview of institutional arrangements and practices in the Nordic countries. NORDRESS, Reykjavík, Iceland.

Hegger, D. L. T., P. P. J. Driessen, C. Dieperink, M. Wiering, G. T. T. Raadgever, and H. F. M. W. van Rijswick. 2014. Assessing stability and dynamics in flood risk governance: an empirically illustrated research approach. Water Resources Management 28 (12):4127-4142. https://doi.org/10.1007/s11269-014-0732-X

Hoang, H., and B. Antoncic. 2003. Network-based research in entrepreneurship: a critical review. Journal of Business Venturing 18:165-187. https://doi.org/10.1016/S0883-9026(02)00081-2

Hotimsky, S., R. Cobb, and A. Bond. 2006. Contracts or scripts? A critical review of the application of institutional theories to the study of environmental change. Ecology and Society 11(1):41. https://doi.org/10.5751/ES-01718-110141

Ingold, K., J. Balsinger, and C. Hirschi. 2010. Climate change in mountain regions: how local communities adapt to extreme events. Local Environment 15:651-661. https://doi. org/10.1080/13549839.2010.498811

Intergovernmental Panel on Climate Change (IPCC). 2012. Managing the risks of extreme events and disasters to advance climate change adaptation. Cambridge University Press, Cambridge, UK. https://doi.org/10.1017/CBO9781139177245
Intergovernmental Panel on Climate Change (IPCC). 2015. Climate change 2014: mitigation of climate change. Cambridge University Press, Cambridge, UK. https://doi.org/10.1017/ CBO9781107415416

Johannessen, Å., Å. Gerger Swartling, C. Wamsler, K. Andersson, J. T. Arran, D. I. Hernández Vivas, and T. A. Stenström. 2019. Transforming urban water governance through social (tripleloop) learning. Environmental Policy and Governance 29 (2):144-154. https://doi.org/10.1002/eet.1843

Johannessen, Å., and J. J. Granit. 2015. Integrating flood risk, river basin management and adaptive management: gaps, barriers and opportunities, illustrated by a case study from Kristianstad, Sweden. International Journal of Water Governance 3:5-24.

Johansson, R. 2008. Organisationer emellan: om förhandlingar, makt och handlingsutrymme. Studentlitteratur, Lund, Sweden.

Lebel, L., E. Nikitina, C. Pahl-Wostl, and C. Knieper. 2013. Institutional fit and river basin governance: a new approach using multiple composite measures. Ecology and Society 18(1):1. https://doi.org/10.5751/es-05097-180101

Leifeld, P., and V. Schneider. 2012. Information exchange in policy networks. American Journal of Political Science 56:731-744. https://doi.org/10.1111/j.1540-5907.2011.00580.x

Lin, L., and M. Abrahamsson. 2015. Communicational challenges in disaster risk management: risk information sharing and stakeholder collaboration through risk and vulnerability assessments in Sweden. Risk Management 17(3):165-178. https:// doi.org/10.1057/rm.2015.11

Luhmann, N. 1979. Trust and power: two works by Niklas Luhmann. John Wiley \& Sons, Chichester, UK.

Mancilla García, M., J. Hileman, Ö. Bodin, A. Nilsson, and P. R. Jacobi. 2019. The unique role of municipalities in integrated watershed governance arrangements: a new research frontier. Ecology and Society 24(1):28. https://doi.org/10.5751/ES-10793-240128

Metz, F., M. Angst, and M. Fischer. 2020. Policy integration: Do laws or actors integrate issues relevant to flood risk management in Switzerland? Global Environmental Change 61:101945. https://doi.org/10.1016/j.gloenvcha.2019.101945

Meyer, J. W., and B. Rowan. 1977. Institutionalized organizations: formal structure as myth and ceremony. American Journal of Sociology 83(2):340-363. https://doi.org/10.1086/226550

MSB (Swedish Civil Contingencies Agency). 2011a. Vägledning för risk- och sårbarhetsanalyser. MSB, Stockholm, Sweden.

MSB (Swedish Civil Contingencies Agency). 2011b. Vägledning för kommunala handlingsprogram. MSB, Karlstad and Stockhom, Sweden.

Niemczynowicz, J. 1999. Urban hydrology and water management - present and future challenges. Urban Water 1 (1):1-14. https://doi.org/10.1016/S1462-0758(99)00009-6

North, D. C. 1990. Institutions, institutional change and economic performance. Cambridge University Press, Cambridge, UK. https://doi.org/10.1017/CBO9780511808678 
Oliver, C. 1991. Strategic responses to institutional processes. Academy of Management Review 16:145-179. https://doi. org/10.5465/amr.1991.4279002

Oxford English Dictionary. 2014. Oxford dictionary of English. Oxford University Press, Oxford, UK.

Pahl-Wostl, C., L. Lebel, C. Knieper, and E. Nikitina. 2012. From applying panaceas to mastering complexity: toward adaptive water governance in river basins. Environmental Science \& Policy 23:24-34. https://doi.org/10.1016/j.envsci.2012.07.014

Peters, B. G. 2013. Toward policy coordination: alternatives to hierarchy. Policy \& Politics 41(4):569-584. https://doi. org/10.2307/j.ctt1t895hw.13

Petridou, E., P. Becker, and J. Sparf. 2021. Policy entrepreneurs in public administration: a social network analysis. Politics \& Policy 49(2):414-445. https://doi.org/10.1111/polp.12400

Priest, S. J., C. Suykens, H. F. M. W. Van Rijswick, T. Schellenberger, S. B. Goytia, Z. W. Kundzewicz, W. J. Van DoornHoekveld, J.-C. Beyers, and S. Homewood. 2016. The European Union approach to flood risk management and improving societal resilience: lessons from the implementation of the Floods Directive in six European countries. Ecology and Society 21(4):50. https://doi.org/10.5751/ES-08913-210450

Renn, O. 2008. Risk governance: coping with uncertainty in a complex world. Routledge, London, UK. https://doi. org/10.4324/9781849772440

Robins, G., J. M. Lewis, and P. Wang. 2012. Statistical network analysis for analyzing policy networks. Policy Studies Journal 40 (3):375-401. https://doi.org/10.1111/j.1541-0072.2012.00458.x

Rowley, T. J. 1997. Moving beyond dyadic ties: a network theory of stakeholder influences. Academy of Management Review 22:887-910. https://doi.org/10.5465/amr.1997.9711022107

Scott, J. 2004. Studying power. Pages 82-91 in K. Nash and A. Scott, editors. The Blackwell companion to political sociology. Blackwell, Oxford, UK. https://doi.org/10.1002/9780470696071. $\underline{\mathrm{ch} 8}$

Scott, W. R. 2014. Institutions and organizations: ideas, interests, and identities. SAGE, Los Angeles, California, USA.

Selznick, P. 1992. The moral commonwealth: social theory and the promise of community. University of California Press, Berkeley, California, USA.

Stinchcombe, A. L. 2000. Social structure and organizations. Pages 229-259 in J. A. C. Baum and F. Dobbin, editors. Economics meets sociology in strategic management (Advances in strategic management, Vol. 17). Emerald, Bingley, UK. https://doi. org/10.1016/S0742-3322(00)17019-6

Taylor, F. W. 1919. The principles of scientific management. Harper \& Brothers, New York, New York, USA.

Thaler, T., and M. Levin-Keitel. 2016. Multi-level stakeholder engagement in flood risk management - a question of roles and power: lessons from England. Environmental Science \& Policy 55 (2):292-301. https://doi.org/10.1016/j.envsci.2015.04.007
Tolbert, P. S., and L. G. Zucker. 1996. The institutionalization of institutional theory. Pages 175-190 in S. R. Clegg, C. Hardy, and W. R. Nord, editors. Handbook of organization studies. SAGE, Thousand Oaks, California, USA.

van de Ven, A. H., and R. Garud. 1994. The coevolution of technical and institutional events in the development of an innovation. Pages 425-443 in J. A. C. Baum and J. V. Singh, editors. Evolutionary dynamics of organizations. Oxford University Press, Oxford, UK.

Weber, M. 1978. Economy and society: an outline of interpretative sociology. University of California Press, Berkeley, California, USA.

Weick, K. E. 1976. Educational organizations as loosely coupled systems. Administrative Science Quarterly 21(1):1-19. https://doi. org/10.2307/2391875

White, H. C. 1997. Can mathematics be social? Flexible representations for interaction process and Its sociocultural constructions. Sociological Forum 12(1):53-71.

Widmer, A., L. Herzog, A. Moser, and K. Ingold. 2019. Multilevel water quality management in the international Rhine catchment area: how to establish social-ecological fit through collaborative governance. Ecology and Society 24(3):27. https://doi. org/10.5751/ES-11087-240327

Yin, R. K. 2003. Case study research: design and methods. Third edition. SAGE, Thousand Oaks, California, USA.

Young, O. R., and A. Underdal. 1997. Institutional dimensions of global change. International Human Dimensions Programme, Bonn, Germany.

Zucker, L. G., and O. Schilke. 2019. Towards a theory of microinstitutional processes: forgotten roots, links to socialpsychological research, and new ideas. Pages 371-389 in P. Haack, J. Sieweke, and L. Wessel, editors. Microfoundations of institutions (Research in the sociology of organizations, Vol. 65B). Emerald, Bingely, UK. https://doi.org/10.1108/

S0733-558X2019000065B029 